\title{
Regional climate model projections for the State of Washington
}

\author{
Eric P. Salathé Jr. • L. Ruby Leung • \\ Yun Qian • Yongxin Zhang
}

Received: 4 June 2009 / Accepted: 23 March 2010 / Published online: 5 May 2010

(C) Springer Science+Business Media B.V. 2010

\begin{abstract}
Global climate models do not have sufficient spatial resolution to represent the atmospheric and land surface processes that determine the unique regional climate of the State of Washington. Regional climate models explicitly simulate the interactions between the large-scale weather patterns simulated by a global model and the local terrain. We have performed two 100-year regional climate simulations using the Weather Research and Forecasting (WRF) model developed at the National Center for Atmospheric Research (NCAR). One simulation is forced by the NCAR Community Climate System Model version 3 (CCSM3) and the second is forced by a simulation of the Max Plank Institute, Hamburg, global model (ECHAM5). The mesoscale simulations produce regional changes in snow cover, cloudiness, and circulation patterns associated with interactions between the largescale climate change and the regional topography and land-water contrasts. These changes substantially alter the temperature and precipitation trends over the region relative to the global model result or statistical downscaling. To illustrate this effect, we analyze the changes from the current climate (1970-1999) to the mid twentyfirst century (2030-2059). Changes in seasonal-mean temperature, precipitation, and snowpack are presented. Several climatological indices of extreme daily weather are also presented: precipitation intensity, fraction of precipitation occurring in
\end{abstract}

E. P. Salathé Jr. $(\bowtie)$

JISAO/CSES Climate Impacts Group, University of Washington, Seattle, WA, USA

e-mail: salathe@washington.edu

L. R. Leung · Y. Qian

Atmospheric Science and Global Change Division, Pacific Northwest National Laboratory,

Richland, WA, USA

Y. Zhang

Research Applications Laboratory, National Center for Atmospheric Research,

Boulder, CO, USA 
extreme daily events, heat wave frequency, growing season length, and frequency of warm nights. Despite somewhat different changes in seasonal precipitation and temperature from the two regional simulations, consistent results for changes in snowpack and extreme precipitation are found in both simulations.

\section{Introduction}

The climate of the State of Washington is exceptional in its range of variability. Geographical climate zones range from temperate coastal rain forests to glaciated mountain ranges to arid scrublands. Temporally, the state experiences a large range in precipitation over the annual cycle and significant year-to-year variability associated with the El Niño-Southern Oscillation and modulated by the Pacific Decadal Oscillation. The region is characterized by its complex terrain, coastlines, varied ecological landscapes, and land use patterns. These features interact at all spatial and temporal scales with weather systems from the North Pacific and continental interior to establish the regional climate of the state. To understand how climate change will affect the state, we must understand how these interactions modulate the large-scale global climate change patterns simulated by global climate models.

Global climate models do not account for the atmospheric processes that determine the unique spatially heterogeneous climatic features of Washington. Elsewhere in this issue (Elsner et al. 2010), climate datasets with high spatial resolution (on a $0.0625^{\circ}$ grid) are produced using a combination of global climate simulations and gridded observations by way of statistical downscaling methods (Mote and Salathé 2010). Statistical methods have been successfully employed in the Pacific Northwest (Salathé 2003, 2005; Widmann et al. 2003; Wood et al. 2004) and other regions (Giorgi and Mearns 1999). Statistical downscaling is based on fine-scale data derived using assumptions about how temperature and precipitation vary over complex terrain in order to interpolate the sparse station network (about $50-\mathrm{km}$ spacing) to a $0.0625^{\circ}$ grid. Information simulated by the coarse-resolution global models (with output on a 100-to-300 km grid) is then used to project the future climate. This approach represents the mean climate and local regimes quite well but does not take into account how the terrain influences individual weather systems. Mesoscale process involving land and water surface characteristics, such as orographic precipitation, convergence zones, snow-albedo feedbacks, and cold air drainage, are likely to respond to the changing large-scale climate (see, for example, Leung et al. 2004 and Salathé et al. 2008). Since mesoscale processes are not explicitly represented in global models and statistical downscaling, their role in determining regional climate change is not fully accounted for with these methods. The motivation for applying regional climate models, therefore, is to simulate these processes and to understand their role in regional climate change. In the typical regional climate modeling design, as used here, mesoscale processes do not feedback onto the global climate simulation, and large-scale features that depend on these feedbacks cannot be properly represented. However, many important feedbacks operate at the local scale, such as snow-albedo feedback, and these can substantially modify the regional climate projection.

A regional climate model is similar to a global climate model in that it simulates the physical processes in the climate system. Regional climate models cover a limited 
area of the globe and are run at much finer spatial resolution-1-50 km grid spacing as opposed to $100-300 \mathrm{~km}$ grid spacing in a global model-thus they can simulate the interactions between large-scale weather patterns and local terrain features not resolved by global models. Global model output data are used to force the regional model at its boundaries and the regional model downscales the global model by producing fine-scale weather patterns consistent with the coarse-resolution features in the global model. The disadvantages of a regional climate model are that it is computationally expensive and cannot explicitly remove systematic differences (biases) between the global model and observations as statistical methods can. Thus, for many applications, some bias correction must be applied to the results, to remove the combined biases of the global and regional model. This approach is used in Rosenberg et al. (2010) using data from the WRF simulations presented here. Furthermore, due to the computational demands of regional models, there is a trade-off in using them for impacts studies between long simulations at high model resolution, to better simulate local effects, and a large ensemble of simulations using multiple regional and global models, to better represent the range of uncertainty. In this study, we have used only two regional simulations, but these have been performed for very long time periods and at relatively high resolution. While this approach limits our ability to understand the effects of inter-model differences, such effects are explored in Mote and Salathé (2010), Elsner et al. (2010), and Vano et al. (2010). As such, this paper complements the wider range of climate projections presented in those papers.

In this paper, we report results from two 100-year simulations with a regional climate model using two different global models to provide forcing at the boundaries. Both regional simulations use the Weather Research and Forecasting (WRF) model developed at the National Center for Atmospheric Research (NCAR). This model includes advanced representations of cloud microphysics and land-surface dynamics to simulate the complex interactions between atmospheric processes like precipitation and land surface characteristics such as snow cover and soil moisture. One simulation is forced by the NCAR Community Climate System Model version 3 (CCSM3) and will be referred to as CCSM3-WRF and the second is forced by a simulation of the Max Plank Institute, Hamburg, global model (ECHAM5), referred to as ECHAM5-WRF. The WRF model configuration is very similar for both simulations, with modifications described below. The ECHAM5-WRF simulation was performed on a $36-\mathrm{km}$ grid while the CCSM3-WRF simulation was on a $20-\mathrm{km}$ grid. Thus, differences between the two simulations are primarily attributable to the forcing models and the grid spacing used. The ECHAM5-WRF grid encompasses the continental US while the CCSM3-WRF grid covers the western US. Here we analyze results only for the Pacific Northwest. We base our analysis on differences in the regional simulations for the present climate, defined as the 30-year period 1970 to 1999 , and the mid twenty-first century, the 30-year period 2030-2059.

High spatial resolution in the regional model is critical to simulating mesoscale processes and adding value over the global model. For example, Leung and Qian (2003) showed substantial improvement in simulating precipitation and snowpack for the Pacific Northwest when reducing the grid spacing in a regional model. The 20-km grid CCSM3-WRF and 36-km ECHAM5-WRF grid spacing is sufficient to resolve the major mountain ranges and coastlines of the Pacific Northwest that are important to the climate of Washington. 


\section{Model configuration}

\subsection{Forcing models}

The atmospheric component of ECHAM5/MPI-OM is the fifth-generation general circulation model developed at the European Centre for Medium-Range Weather Forecasts and the Max Planck Institute for Meteorology (Roeckner et al. 1999, 2003), and the ocean component is the Max Planck Institute Ocean Model (MPI-OM; Marsland et al. 2003). Here we will refer to the coupled model simply as ECHAM5. For the present climate (1970-1999), we used an ECHAM5 simulation of the 20th century with historical forcing; for the twenty-first century, we used a simulation with the Special Report on Emissions Scenarios (SRES) A1B emissions scenario (Nakicenovic et al. 2000). ECHAM5 was run at T63 spectral resolution, which corresponds to a horizontal grid spacing of approximately $140 \times 210 \mathrm{~km}$ at mid-latitudes, and 32 levels in the vertical. Model output at 6-hourly intervals was obtained from the CERA WWW Gateway at http://cera-www.dkrz.de/CERA/index.html; the data are managed by World Data Center for Climate http:/www.mad.zmaw.de/wdcc/.

The NCAR Community Climate System Model Version 3 (CCSM3) consists of the Community Atmospheric Model (CAM), the Parallel Ocean Program (POP), the Community Land Model (CLM), and the Community Sea Ice Model (CSIM) coupled through a flux coupler to simulate the atmosphere, ocean, cryosphere, and land processes, and their interactions (Collins et al. 2006). The atmospheric model (CAM) that provides boundary conditions to CCSM3-WRF was run at a horizontal grid resolution of T85, which corresponds roughly to a grid spacing of $150 \mathrm{~km}$ in the mid-latitudes, with 26 vertical levels. For the present climate (1970-1999), CCSM3-WRF was forced with one of the 10 ensemble CCSM3 simulations of the twentieth century with historical radiative forcing. For the future climate, we used one of five ensemble simulations prepared for the IPCC AR4 using the SRES A2 emission scenario. Model output at 6-hour intervals is available from the NCAR mass storage, the Program for Climate Model Diagnostic and Intercomparison (PCMDI) AR4 global simulation archives (http://www-pcmdi.llnl.gov/), and the Earth System Grid (ESG).

The two models used to force the regional climate model (CCSM3 and ECHAM5) are compared with a set of 19 global models in Mote and Salathé (2010), who show that both models provide realistic simulations of the twentieth century climate. Compared to the multi-model average for the Pacific Northwest (Table 1), the ECHAM5 A1B simulation projects a low temperature increase and a high precipitation increase while the CCSM3 A2 simulation projects a relatively warmer and drier future.

Table 1 Pacific Northwest annual mean changes in temperature and precipitation from 1970-1999 to 2030-2059 for ECHAM5 and CCSM3 compared to 19-model averages in Mote and Salathé (2010)

\begin{tabular}{llc}
\hline & Temperature $\left({ }^{\circ} \mathrm{C}\right)$ & Precipitation $(\%)$ \\
\hline ECHAM5 A1B & 1.58 & 3.0 \\
CCSM3 Run5 A2 & 2.5 & -0.8 \\
19-Model A1B & 2.24 & 1.9 \\
19-Model B1 & 1.68 & 2.0 \\
\hline
\end{tabular}


Since CCSM3 was run for an ensemble of simulations, we can compare the simulation used here to the full ensemble. Differences among ensemble members reflect the inherent variability in the simulated climate given the same radiative forcing, and each simulation can be taken as an equally likely projection of the climate. Of the parameters discussed here, precipitation shows by far the greatest variation across the ensemble, consistent with the large observed natural variability in regional precipitation. While precipitation from the global model is not used in forcing the regional model, the winds and moisture fields are used, and this ensures an overall compatibility of the global and regional precipitation simulation. The ensemble member used for this study (run 5) differs from the ensemble mean most significantly in November precipitation over the Pacific Northwest. The CCSM3 SRES A2 ensemble mean shows a modest increase in autumn and spring precipitation with decreases in the winter and summer, which is generally consistent with the multi-model ensemble mean discussed in Mote and Salathé (2010). For the ensemble member used to force WRF, the 1970-1999 November mean Pacific Northwest precipitation is the lowest and the 2030-2059 mean is the highest in the ensemble. Thus, the change in November precipitation is high compared to the ensemble mean. In the results below, we find that this increase in precipitation has a marked influence on the simulated regional climate change; these results must be interpreted as the combined influence of systematic climate change and internal climate variability.

\subsection{Regional model}

The WRF model is a state-of-the-art mesoscale numerical weather prediction system designed to serve both operational forecasting and atmospheric research needs (http://www.wrf-model.org). This model has been developed and used extensively in recent years for regional climate simulation (Leung et al. 2006). WRF is a nonhydrostatic model with multiple choices for physical parameterizations suitable for applications across scales ranging from meters to thousands of kilometers. The physics package includes microphysics, convective parameterization, planetary boundary layer (PBL), land surface models (LSM), and longwave and shortwave radiation.

In this work, the microphysics and convective parameterizations used were the WRF Single-Moment 5-class (WSM5) scheme (Hong et al. 2004) and the KainFritsch scheme (Kain and Fritsch 1993). The WSM5 microphysics explicitly simulates water vapor, cloud water, rain, cloud ice, and snow. The Kain-Fritsch convective parameterization utilizes a simple cloud model with moist updrafts and downdrafts that includes the effects of detrainment and entrainment. The land-surface model used was the NOAH (National Centers for Environmental Prediction-NCEP, Oregon State University, Air Force, and Hydrologic Research Lab) LSM (Chen and Dudhia 2001). This is a four-layer soil temperature and moisture model with canopy moisture and snow cover prediction. It includes root zone, evapotranspiration, soil drainage, and runoff, taking into account vegetation categories, monthly vegetation fraction, and soil texture. A modification is included so that soil temperatures vary at the lower boundary of the soil column (8-m depth) in accordance with the evolving climatological surface temperature. The PBL parameterization used was the YSU 
(Yonsei University) scheme (Hong and Pan 1996). This scheme includes countergradient terms to represent heat and moisture fluxes due to both local and non-local gradients. Atmospheric shortwave and longwave radiation were computed by the NCAR CAM (Community Atmospheric Model) shortwave scheme and longwave scheme (Collins et al. 2004).

The most interesting differences between the ECHAM5-WRF and CCSM3-WRF simulations are those due to the global model used to force the regional simulation. However, there are minor technical differences in the WRF model configurations used at Pacific Northwest National Laboratory for the CCSM3-WRF and used at the University of Washington for the ECHAM5-WRF simulations. First, the CCSM3WRF simulation used the SRES A2 scenario while ECHAM5-WRF used the SRES A1B emissions scenario. The effect of these different emissions scenarios on the simulated climate is minor since the two emissions scenarios do not begin to diverge until the mid twenty-first century. The difference between the PNW-mean annual warming from 1970-1999 to 2030-2059 for the CCSM3 A2 simulation used for this paper and the CCSM3 A1B simulation used in the remainder of the assessment is less than $1^{\circ} \mathrm{C}$. Secondly, the ECHAM5-WRF simulation follows the methods of the MM5-based mesoscale climate modeling described in Salathé et al. (2008): Nested grids and interior nudging are used to match the WRF simulation to the global model. The CCSM3-WRF uses a single model domain with a wider buffer zone for the lateral boundaries to increase the constraints from the global climate simulation. The relaxation coefficients of the nudging boundary conditions follow a linear-exponential function to smoothly blend the large-scale circulation from the global simulation and the regional simulation. As seen below, both simulations closely follow the forcing model, so both nudging and the extended buffer zone are successful methods of constraining the regional simulation.

\section{Model evaluation}

To establish whether the regional climate simulations can reproduce the observed climate of the Pacific Northwest, we compared the two simulations for the winter (December-January-February, DJF) and summer (June-July-August, JJA) to gridded observations averaged for the period 1970-1999, in a similar manner to Leung et al. (2003a, b). The gridded data consist of station observations interpolated to a 1/16-degree grid using an empirical model for the effects of terrain on temperature and precipitation (Daly et al. 1994; Elsner et al. 2010). Since the CCSM3 and ECHAM5 simulations are from free-running climate models, the observed temporal sequence (i.e. at daily to interannual time scales) is not reproduced. However, for averages over a period of 30 years, most natural and internal model variability should be removed and we expect any differences among the simulations and gridded observations to be the result of model deficiencies and, to some degree, differences in grid resolutions.

It is important to note that a regional model does not explicitly remove any bias in the forcing model, except where such bias is due to unresolved processes, and may introduce additional biases. This comparison, therefore, evaluates both the regional model and the global forcing model. Some uncertainty in the evaluation is introduced in using gridded observations as opposed to station observations since the gridding 
procedure interpolates between the sparse station network based on a simple terrain model for temperature and precipitation.

An alternative method for evaluation of the WRF regional climate simulation, based on station observations, may be found in Zhang et al. (2009), who use the same WRF implementation used for the ECHAM5-WRF simulations, but forced by an atmospheric reanalysis, in order to isolate deficiencies in the mesoscale model from errors in the forcing model. That study found that $T_{\max }$ and $T_{\min }$ simulated by WRF compare well with the station observations. Warm biases of $T_{\max }$ are noted in WRF simulations between February and June with cold biases during the rest of the year. Warm biases of $T_{\min }$ prevail throughout the year. The temporal correlation between the simulated and observed daily precipitation is low; however, the correlation increases steadily for longer averaging times, showing good representation of seasonal and interannual variability.

Figure 1 shows the winter (DJF) and summer (JJA) temperature simulated by CCSM3-WRF (left) and ECHAM5-WRF (middle) simulation in comparison to the gridded observations (right). The bottom two panels show simulated and observed temperature and the ECHAM5-WRF terrain along a transect of Washington at $47.8^{\circ} \mathrm{N}$; observed precipitation has been averaged over a latitude band to reflect the model resolution. Overall, the temperature is well represented in the simulations: the influence of the major geographical features is captured, and the seasonal cycle is reproduced. Both models exhibit a substantial cold bias relative to the gridded observations. In DJF, this bias is evident over the Cascade crest and Southeast Washington. Any bias in the global forcing models is inherited by the WRF simulation, so this comparison depends on combined deficiencies in the forcing model and regional model.

Figure 2 shows the corresponding results for simulated and observed 1970-1999 precipitation. Again, the overall magnitude of precipitation and its geographical distribution are well characterized by the simulations for both seasons. Both models are unable to resolve the large precipitation peak over the Olympics, but do represent the maximum over the Cascades. The finer grid spacing in the CCSM3-WRF simulation reproduces the intensity along the crests of the Cascades and Olympics better than the ECHAM5-WRF simulation although precipitation is over estimated in the southern Cascades of Oregon. Both models also do well in producing the peak precipitation on the windward slopes of the Cascade Range with a rapid drop in the lee. The CCSM3-WRF result produces comparable peaks for each range while the ECHAM5-WRF simulation produces a somewhat smaller maximum over the Olympics due to its coarser grid spacing. Compared to the Cascades, the Olympics are lower elevation, have a smaller geographic extent, and are an isolated "hill" in the models rather than a ridge as for the Cascades. As a result, finer grid spacing is required to simulate orographic precipitation over the Olympics than over the Cascades. As shown in Leung and Qian (2003), as model resolution improves, the maximum over the Olympics becomes larger than that over the Cascades, in accordance with observations.

Figure 3, top panels, shows the 1970-1999 average April 1 snowpack from the two regional models expressed as millimeters of snow-water equivalent (SWE). SWE follow the spatial pattern of precipitation, with the CCSM3-WRF (left) clearly showing more tightly localized and higher SWE values than the ECHAM5-WRF (right) simulation. For comparison, we include two baseline snow climatologies. 

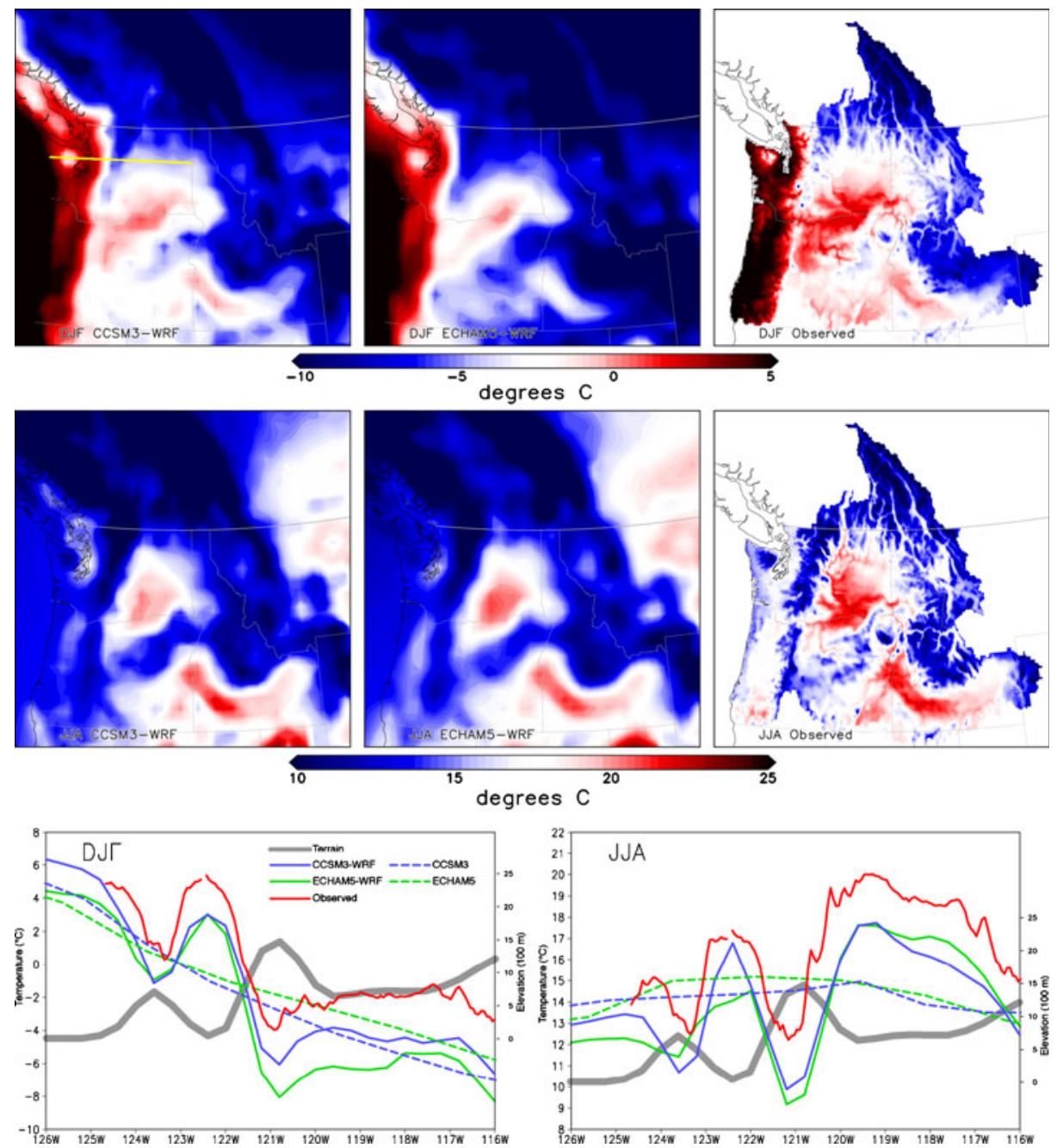

Fig. 1 Seasonal mean temperature $\left({ }^{\circ} \mathrm{C}\right)$ in 1970-1999 for DJF (top row) and JJA (middle row) from CCSM3-WRF (column 1), ECHAM5-WRF (column 2) and gridded observations (column 3). Bottom row, Observed temperature and simulated temperature from both regional models and global forcing models along a West-East transect of the State of Washington at $47.8^{\circ} \mathrm{N}$ latitude (yellow line, upper-left panel). Terrain height is indicated by the thick grey line

Figure 3, bottom left, shows the 1970-1999 average April 1 SWE computed from the VIC hydrologic model (Elsner et al. 2010), run at $0.0625^{\circ}$ (approximately $7 \mathrm{~km}$ $\times 5 \mathrm{~km}$ ) grid spacing and using the temperature and precipitation shown in Figs. 1 and 2.

Figure 3, bottom right, shows April average snow water equivalent for the period 1979-1997 from a product employed operationally at the Canadian Meteorological Centre (CMC). This 0.25-degree (approx $28 \times 20 \mathrm{~km}$ ) gridded dataset combines in situ daily observations from $\sim 8,000$ US cooperative stations and Canadian climate stations and first-guess fields with an optimum interpolation scheme developed by 

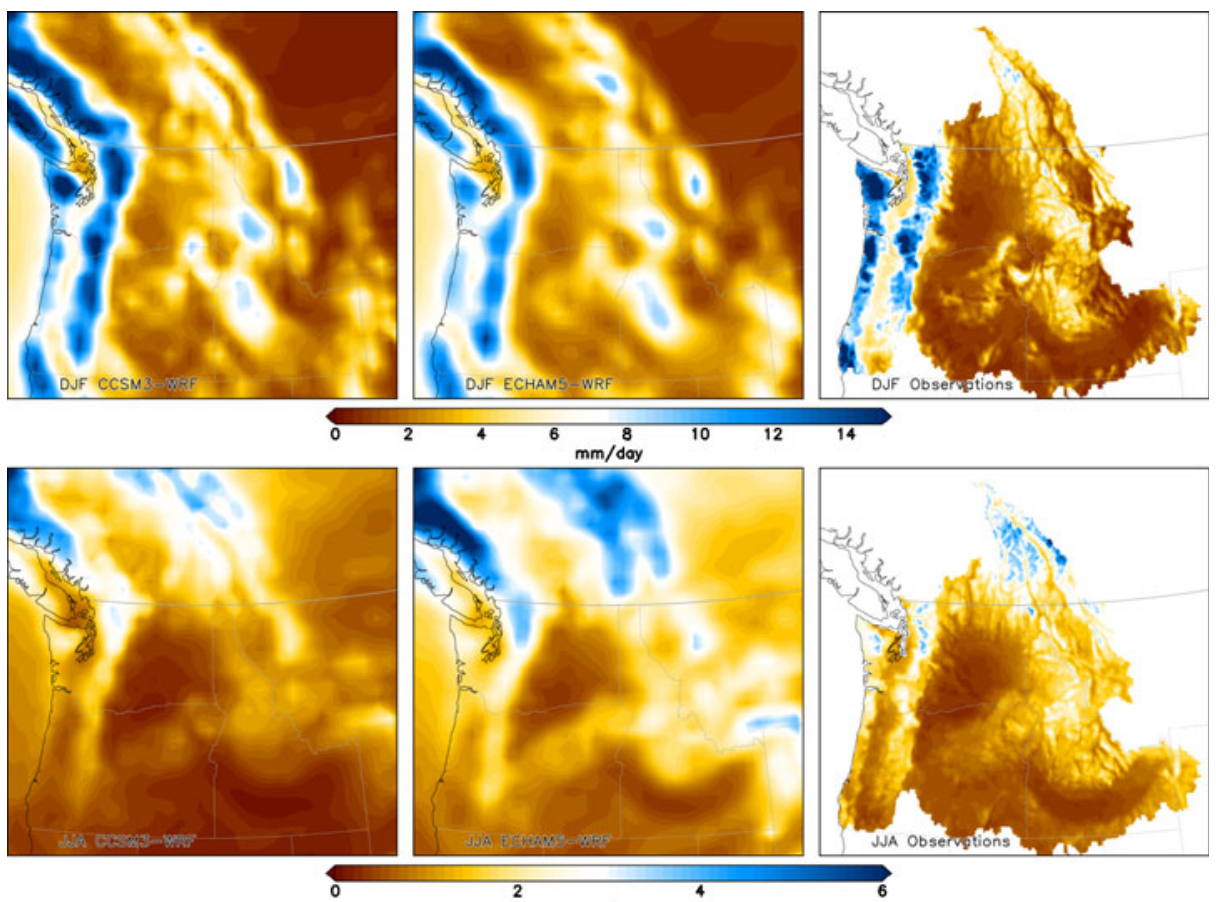

$$
\mathrm{mm} / \text { doy }
$$

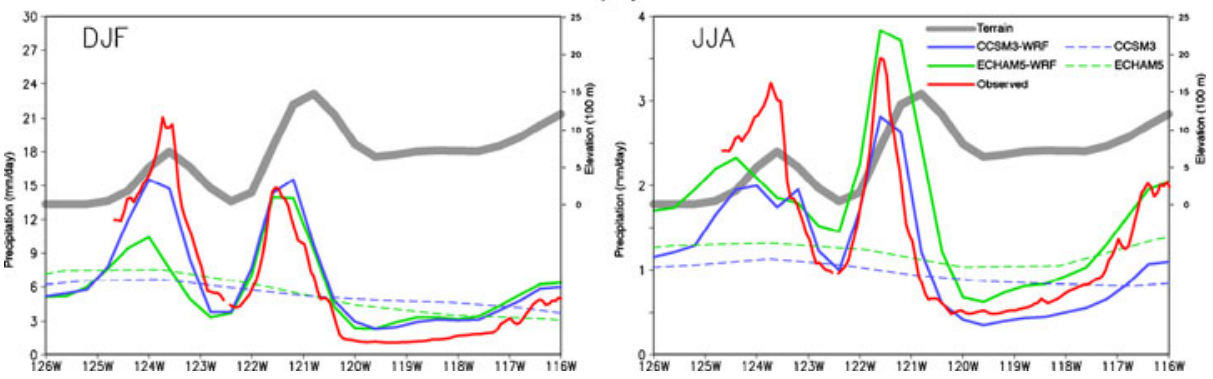

Fig. 2 Seasonal mean precipitation (millimeters/day) in 1970-1999 for DJF (top row) and JJA ( middle row) from CCSM3-WRF (column 1), ECHAM5-WRF (column 2) and gridded observations (column 3). Bottom row, Observed precipitation and simulated precipitation from both regional models and global forcing models along a West-East transect of the State of Washington at $47.8^{\circ} \mathrm{N}$ latitude. Terrain height is indicated by the thick grey line

Brown et al. (2003). Only the monthly-means are available for the CMC data; the April average from the WRF simulations is qualitatively similar to the April 1 field, so we use this for comparison. Note that the VIC-based SWE uses a much finer grid spacing than the regional models while the CMC grid spacing is similar to the models.

While the geographical extent of snow cover is well represented in the WRF simulations, there is clearly an underestimate at mid elevations. This deficiency is consistent with the coarse topographic resolution in the regional models and the precipitation results above. Accordingly, the CCSM3-WRF simulation, which has finer grid spacing, does somewhat better than the ECHAM5-WRF simulation. The CMC data also compares better to the WRF simulations than the VIC simulation, 

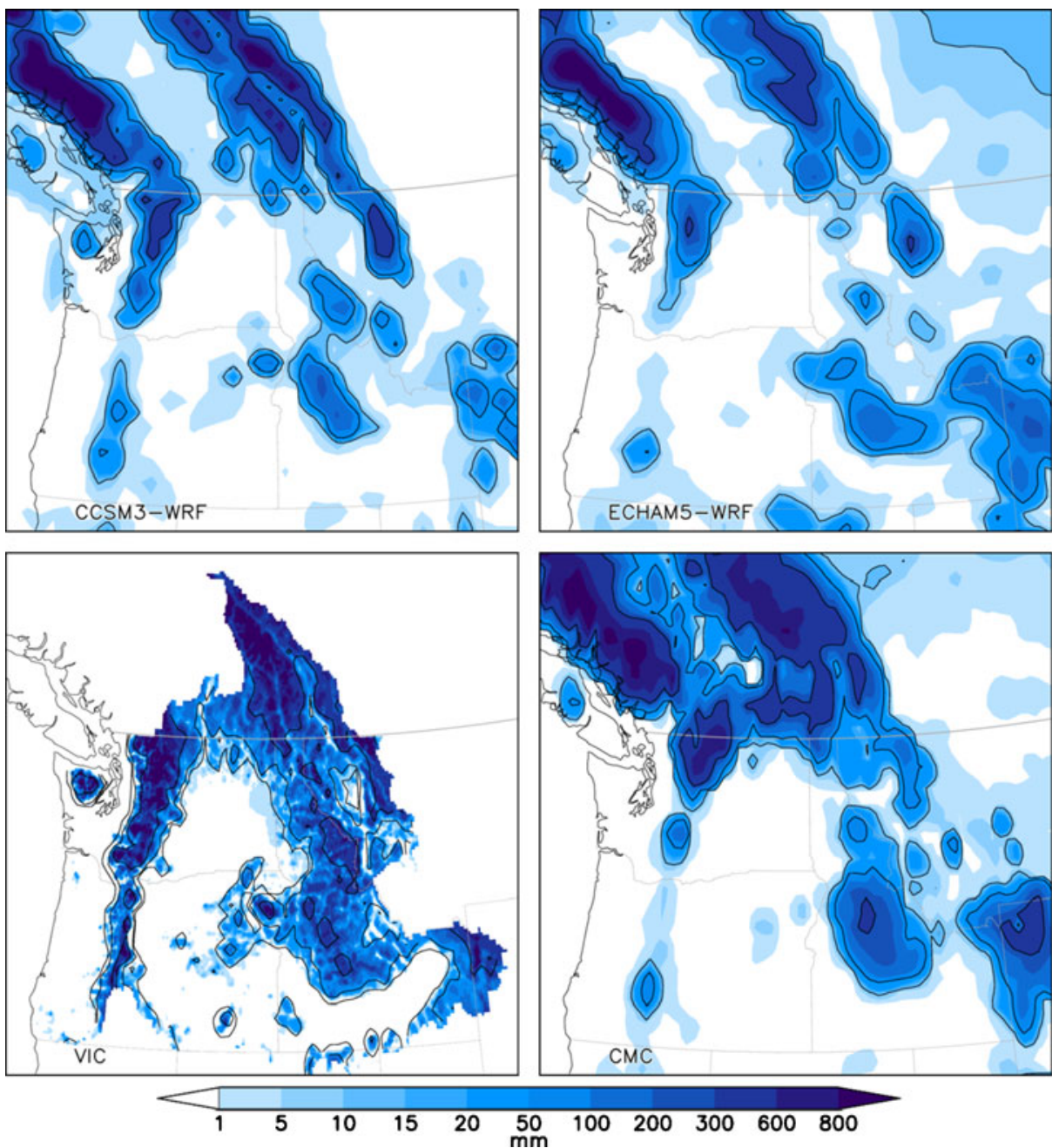

Fig. 3 Simulated April 1 snow water equivalent (millimeters) in 1970-1999 from CCSM3-WRF (top left), ECHAM5-WRF (top right), the VIC model forced by the gridded observations in Figs. 1 and 2 (bottom left). The 1979-1997 average April SWE from the Canadian Meteorological Centre snow analysis (bottom right). Contour lines are drawn at 10, 50, and $300 \mathrm{~mm}$

consistent with the similar spatial resolution of the models and this gridded data product.

\section{Seasonal patterns of climate change for 2030-2059}

\subsection{Precipitation}

Precipitation changes in the regional simulations for 2030-2059 include a pronounced seasonality and considerable variation across the region (Fig. 4). Both CCSM3-WRF 


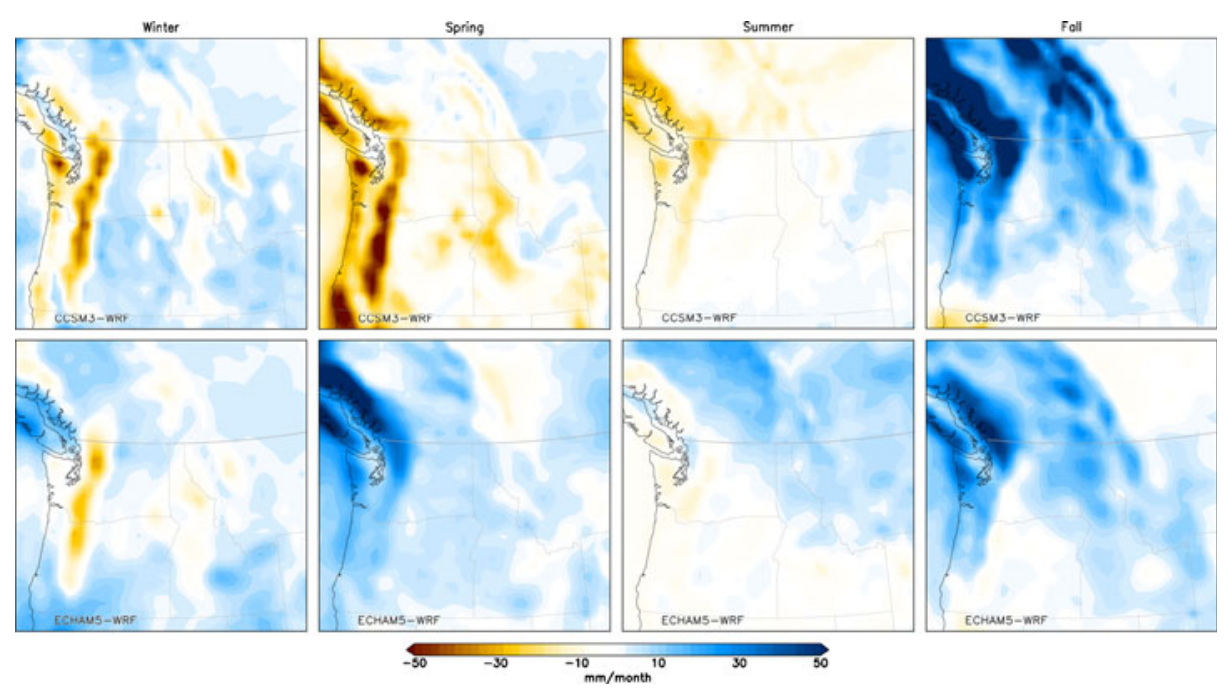

Fig. 4 Change in precipitation (millimeters/month) from 1970-1999 to 2030-2059 for CCSM3-WRF (top row) and ECHAM5-WRF (bottom row) for the four seasons

and ECHAM5-WRF produce substantial decreases in DJF precipitation over the Cascade Range and Olympic Mountains and modest increases east of the Cascades. The two simulations produce opposite responses in spring (MAM), with ECHAM5WRF producing increased precipitation at all locations and CCSM3-WRF a substantial decrease at all locations; in both cases the change has larger magnitudes over the mountain ranges. For summer, the ECHAM5-WRF simulation shows very little change in rainfall while the CCSM3-WRF shows substantial decreases along the mountain ranges. For autumn, both models predict substantial increases in precipitation over the mountain ranges. As we show below, the increases in autumn precipitation result in more intense daily precipitation events.

When compared with the precipitation pattern simulated by the global models, the regional model results are generally consistent with the forcing model. This similarity is due to the dominant role that large-scale storms and moisture flux plays in controlling regionally averaged precipitation in this region. The regional model maintains the large-scale weather systems from the forcing model and simulates fine scale features that derive from interactions with the land surface and mesoscale weather processes. These mesoscale processes yield important differences in the magnitude and distribution of the precipitation changes around the regional topography, which are seen by comparing the global climate model changes (Fig. 5) to the regional model changes (Fig. 4). In general, the precipitation changes in the regional model follow the sign of the changes in the global model but with intensification over complex terrain. Thus, the modest reduction in DJF precipitation in western Washington in both CCSM3 and ECHAM5 is considerably amplified in the Cascade Range and Olympics. Likewise, increases in SON precipitation in both models and in MAM precipitation in ECHAM5 are amplified along the windward sides of the terrain in the regional simulations. 


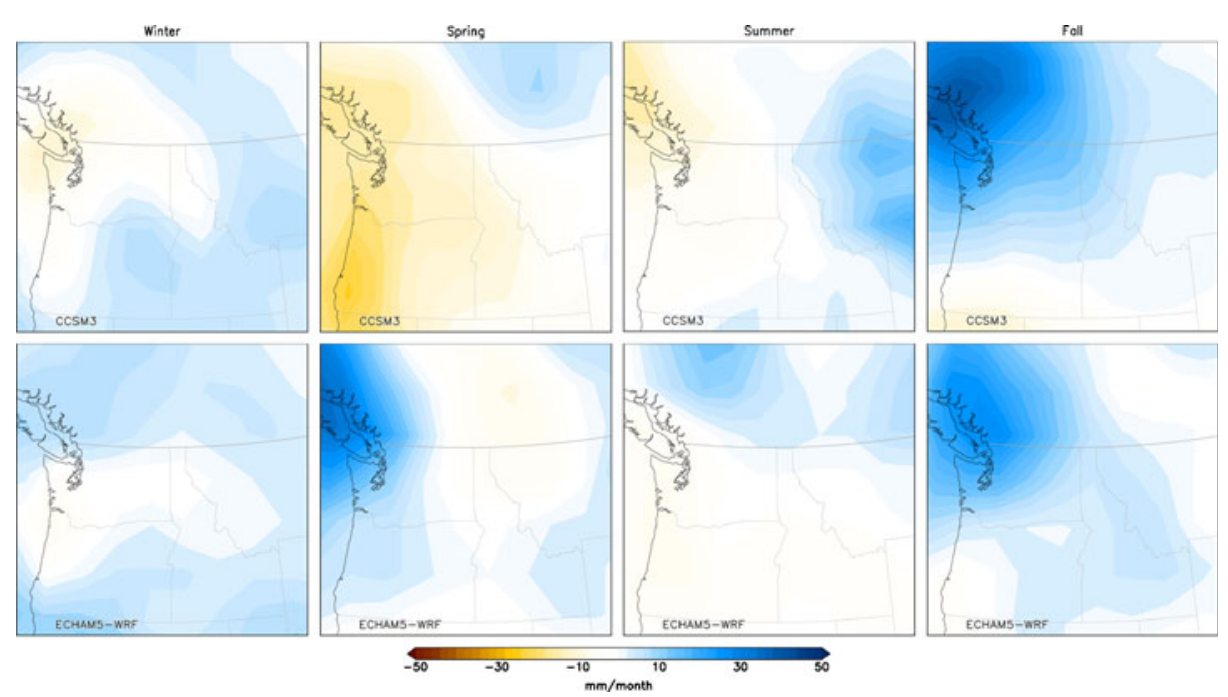

Fig. 5 As for Fig. 4 except for the CCSM3 (top) and ECHAM5 (bottom) global forcing models

In some cases, the regional model produces precipitation changes of the opposite sign from the forcing model. For example, for DJF, both ECHAM5 and CCSM3 show no change or small decreases in precipitation over most of Washington, including eastern Washington. However, both regional models, and especially CCSM3WRF, show an increase in precipitation for eastern Washington. This difference in sign between anomalies east and west of the Cascade Range is also seen in natural climate variability associated with El Niño-Southern Oscillation (ENSO; Leung et al. $2003 \mathrm{a}, \mathrm{b})$. The circulation patterns that generate a decrease in precipitation over the Cascades generally reduce the intensity of the rain shadow, allowing more moisture transport to eastern Washington and consequently more precipitation. For DJF, both simulations produce strong reductions in precipitation throughout the west of the domain despite negligible precipitation changes in the forcing models. This suggests that, while the large-scale moisture flux may increase in a warmer climate, the changes in the circulation patterns, simulated by the global forcing model, are not favorable to orographic precipitation as simulated in the regional model.

To illustrate the importance of the topography on regional precipitation under climate change, we examine a transect across Washington along the latitude $47.8^{\circ} \mathrm{N}$, which crosses both the Olympics and North Cascades. Figure 6 shows the percentage change in precipitation for each of the four seasons and the ECHAM5-WRF topography. The fractional change in precipitation in the regional models varies considerably around the topography in the climate change projections. Using the percentage change removes the large background variation in precipitation along the transect and more clearly shows the climate change signal, or anomaly from the base climate. For DJF (Fig. 6, top left), both simulations show the largest reductions in precipitation on the windward sides of the Olympics and Cascades. The changes become sharply positive in both cases immediately in the lee of the Cascades. For MAM (Fig. 6, top right), the two simulations are quite different. The ECHAM5WRF simulation shows substantial increases on the windward slopes but also in the 
lee of the Cascades. It is likely that different synoptic conditions are responsible for the changes across the transect, but that an overall increase in moisture availability allows increased precipitation under favorable weather patterns. The CCSM3-WRF
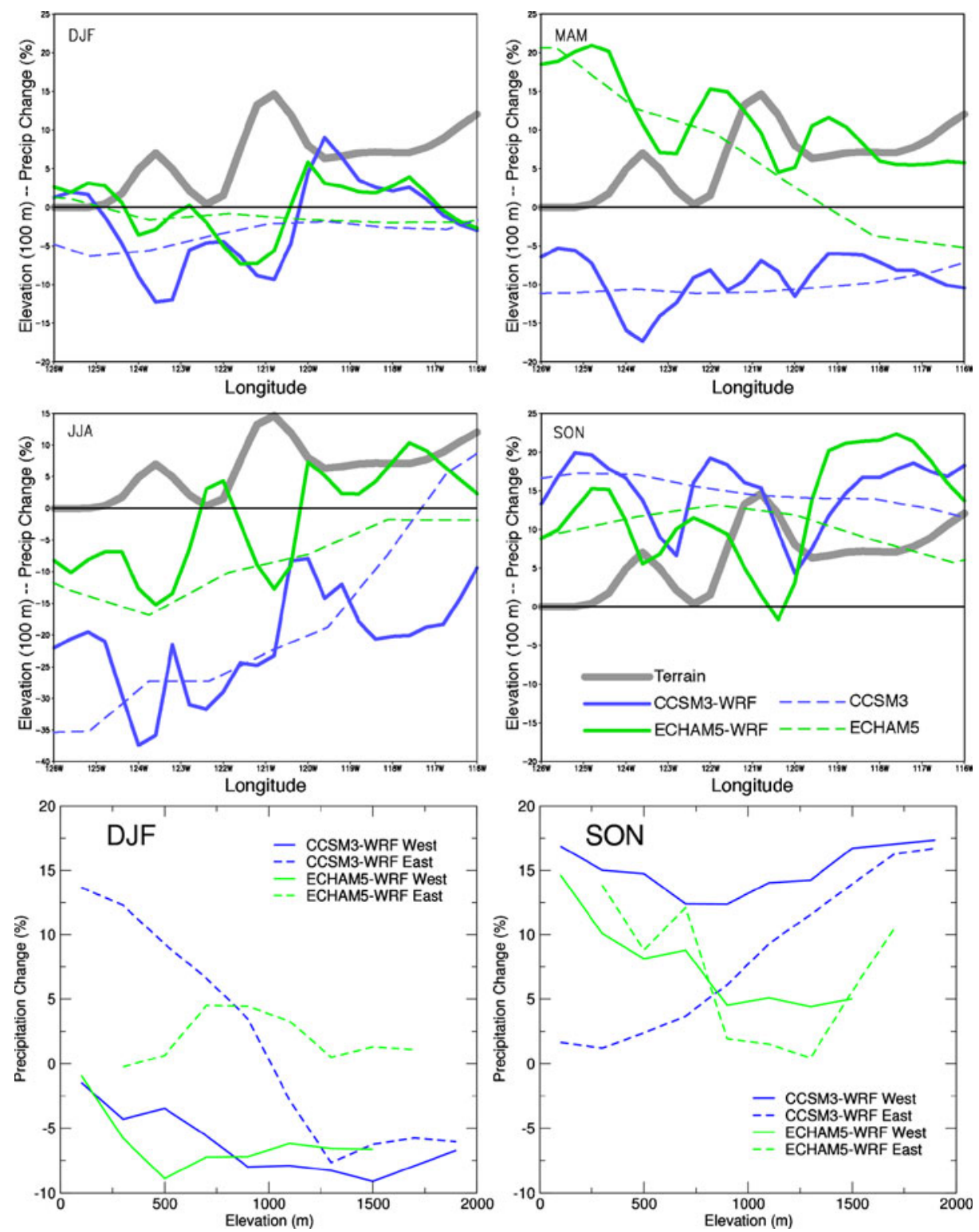

Fig. 6 Upper four panels, Percent change in precipitation from 1970-1999 to 2030-2059 for each season as simulated by the regional models and forcing global models along a West-East transect of the State of Washington at $47.8^{\circ} \mathrm{N}$ latitude. Terrain height is indicated by the thick grey line. Lower two panels, Percent change in DJF (left) and SON (right) precipitation from 1970-1999 to 2030-2059 as a function of elevation averaged over the west (solid) and east (dashed) slopes of the Cascade Range for the CCSM3-WRF (blue) and ECHAM5-WRF (green) simulations 
simulation shows a more uniform decrease in precipitation, with a maximum on the windward slope of the Olympics. Results for both models in SON (Fig. 6, bottom right) are similar to the MAM results for ECHAM5-WRF. Peak precipitation increases are found not only on the windward slopes, but also in Eastern Washington, where the fractional increase is comparable to the increases over the mountains.

Another way to view these results is to consider the changes in precipitation with elevation on the windward (west) and lee (east) slopes of the Cascades. To make this comparison, the percent change in precipitation from the current to future simulation was computed along the entire range in Washington for each side of the crest. These were then averaged in 200-m elevation bands. Results for DJF and SON are shown in Fig. 6, bottom row. Consistent with the transect results, decreases are found over the western slopes for both simulations. For CCSM3-WRF, the decrease diminishes, becoming a substantial increase, moving down slope east of the crest. ECHAM5WRF projects relatively small and uniform increases in precipitation east of the crest. In both cases, these changes represent a weakening of the climatological rain shadow. Leung et al. (2003a, b) suggest that the weakening of the rain shadow is generally associated with changes in the circulation patterns, such as winds shifting to a direction more parallel rather than perpendicular to the dominant ridge, that weaken orographic enhancement. Although the percentage increase on the lee side can be comparable to the decrease on the windward side, the net change in region wide precipitation, which is important for large river basin runoff, is a net increase because precipitation on the upwind slope is significantly higher than that in the rain shadow. For SON, the simulated changes across the Cascades are quite different, with increases on both slopes. The increase is largest on the windward slope, especially for the CCSM3-WRF simulation. Stronger orographic enhancement alone would tend to decrease precipitation on the lee, so this result suggests a combination of changes in moisture availability or moisture source and orographic enhancement are responsible for the simulated changes.

These results give clear evidence that the effect of climate change on precipitation is tightly coupled to the interaction of increased moisture availability and various synoptic weather patterns with the regional topography.

\subsection{Temperature}

Figure 7 shows the temperature change for 2030-2059 in the regional model simulations for the four seasons. There is considerable difference in the temperature response between the two models and with season. These changes are largely the result of the global forcing model and feedbacks within the regional model driven by changes in precipitation, cloudiness, and surface radiation. In the cool season, the spatial pattern of warming in a regional model is strongly linked to changes in snowpack and cloud cover, which alters the surface radiation (Leung et al. 2004; Salathé et al. 2008). For example, where snowpack is lost, either due to warmer temperatures or less precipitation, the albedo is decreased, more solar radiation is absorbed at the surface, and the warming is amplified. For DJF, the CCSM3WRF simulation (Fig. 7, first column, top row) shows amplified warming over the Washington Cascades. This warming exceeds the projection from global forcing model (Fig. 8), but coincides with the region of significant reduction in precipitation (Fig. 4). Thus, the warming is amplified by the loss of precipitation and less frequent 

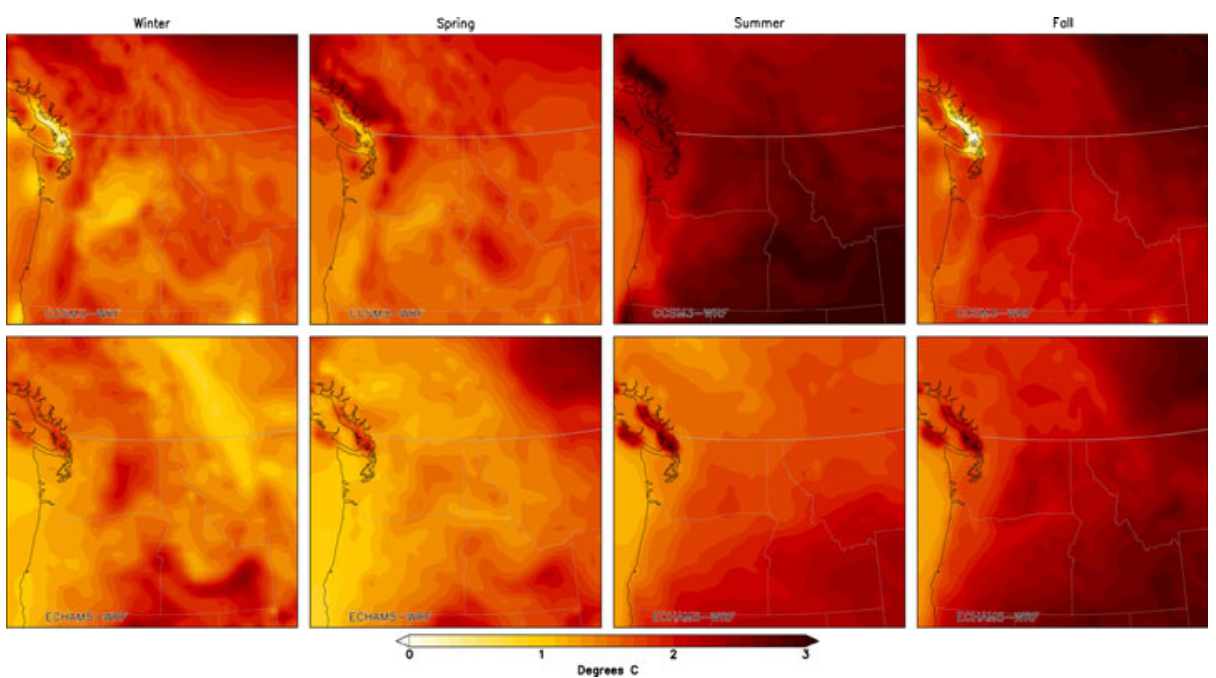

Fig. 7 Change in temperature $\left({ }^{\circ} \mathrm{C}\right)$ from 1970-1999 to 2030-2059 for CCSM3-WRF (top row) and ECHAM5-WRF (bottom row) for the four seasons

snow and clouds over the Cascades. The very different pattern found for DJF in the ECHAM5-WRF simulation (Fig. 7, 1st column, bottom row) follows from the much smaller warming in the ECHAM5 forcing model and smaller decrease in precipitation. In eastern Washington, the CCSM3-WRF simulation shows less warming than the ECHAM5-WRF simulation. This result is consistent with the differences in the forcing from the two models, with ECHAM5 producing more warming along a southeast-northwest axis and the CCSM3 warming mostly in the
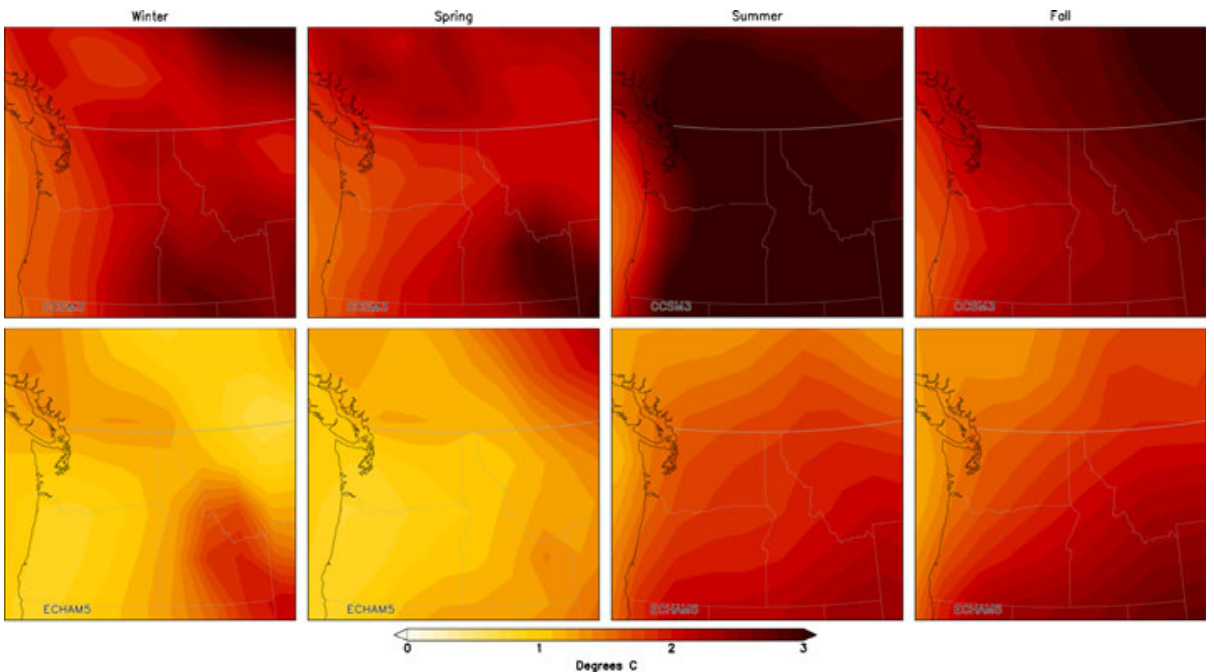

oegrees $c$

Fig. 8 As for Fig. 7 except for the CCSM3 (top) and ECHAM5 (bottom) global forcing models 
eastern portion of the domain. Furthermore, precipitation increases over eastern Washington in the CCSM3-WRF simulation, which implies increased cloud cover and reduced solar heating of the surface.

For MAM (Fig. 7, 2nd column), the differences between the two simulations seen for DJF are accentuated due to the very different precipitation results, with considerable loss of precipitation in CCSM3-WRF and considerable increase in ECHAM5WRF. For JJA, both regional models closely follow the global model, which suggests that mesoscale processes are not as critical to the summer temperature sensitivity. In spring and summer, both the global and regional models indicate less warming in coastal areas than inland. In some cases, the regional models reduce the coastal warming relative to the global model. Nevertheless, warming is still substantial in western Washington and, as shown below, heat waves are projected to become more frequent. For SON, the global forcing models and regional precipitation response are very similar and thus the temperature changes are similar.

\subsection{Snowpack}

Substantial losses of snowpack are found in both regional simulations. Figure 9 shows the change in average spring (MAM) snowpack from the present to future climate. When averaged over Washington, CCSM3-WRF projects a 71\% loss of SWE while ECHAM5-WRF projects a 32\% loss. Since spring snowpack is a good predictor of summertime streamflows, changes for this season indicate the magnitude of the impacts of regional climate change on water resources (see Vano et al. 2010). The CCSM3-WRF simulation (Fig. 9, left) yields much larger snow loss than ECHAM5-WRF (Fig. 9, right) over the entire domain, but particularly for the Cascade and Olympic mountains. In part, this may be due to the finer grid spacing
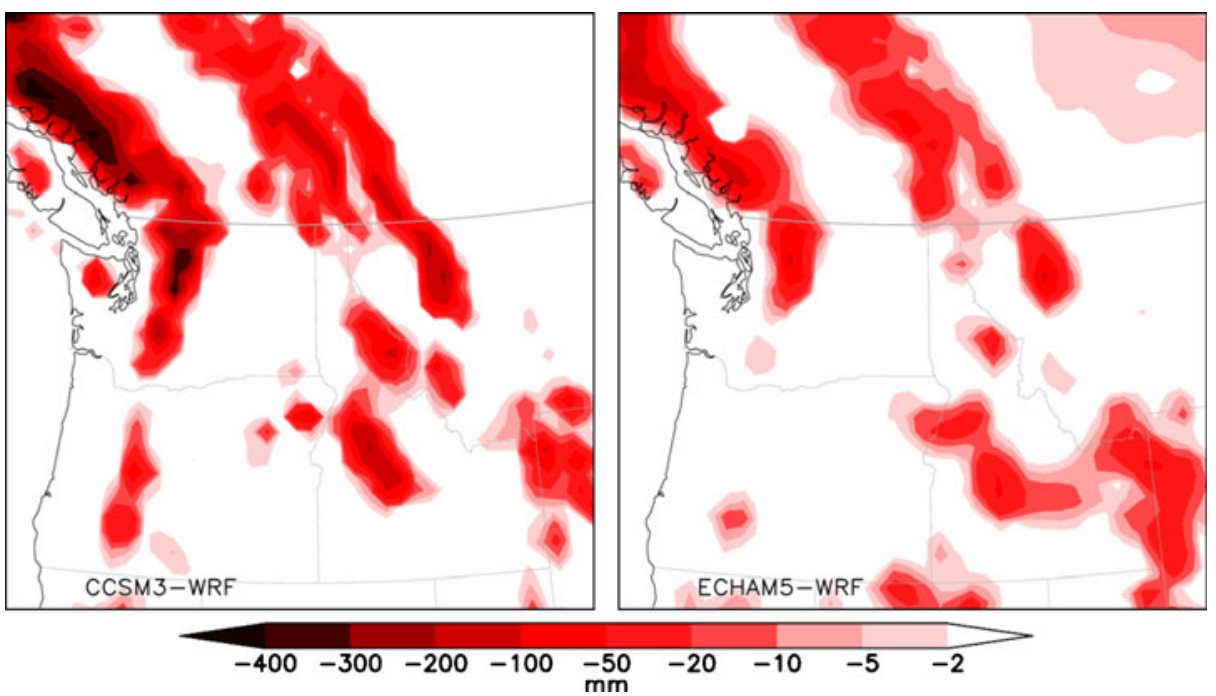

Fig. 9 Change in April 1 snow water equivalent (millimeters) from CCSM3-WRF (left) and ECHAM5-WRF (right) 
in CCSM3-WRF, allowing better representation of smaller terrain features such as the Olympics. However, the 1970-1999 snowpack (Fig. 3) is more similar between the two models than the simulated changes, so model resolution is not the most important effect.

Most of the difference between the two simulations is due to the forcing models and the resulting regional precipitation. Snowpack changes are a result of both changes in precipitation and changes in temperature (Mote et al. 2008). While CCSM3-WRF show somewhat more warming than ECHAM5-WRF and both models show increased autumn precipitation, the dominant effect on the differences in simulated spring snowpack is the difference in precipitation projections. Figure 4 shows a larger reduction in winter and spring precipitation in CCSM3-WRF than in ECHAM5-WRF, and this result dominates the snowpack results. The consensus among global climate models (Mote and Salathé 2010) is for modest increases in cool-season precipitation, so the CCSM3 results presented here are not necessarily characteristic. Nevertheless, despite the increase in cool-season precipitation in ECHAM5-WRF, snowpack decreases over a similar geographical extent as in the much drier CCSM3-WRF projection and about half the magnitude. Thus, while the disparity in precipitation projections in the two models modulates the magnitude of snow loss, warming plays a prominent role in determining future snowpack, counteracting potential increases in precipitation.

The ECHAM5-WRF and CCSM3-WRF projections for cool-season (NovemberMarch) changes in temperature and precipitation and for changes in April 1 SWE are given in Table 1. These may be compared to the results from Elsner et al. (2010) and Casola et al. (2009) as follows. Casola et al. (2009), using simple theoretical arguments, estimate a $16 \%$ loss of snowpack for each $1^{\circ} \mathrm{C}$ of warming. This estimate assumes a $5 \%$ increase in precipitation for each degree of warming. These values may be estimated directly from the data in Elsner et al. (2010) based on computations using a hydrologic model and perturbed historic temperature and precipitation data. From their Tables 4 and 6 for the three time periods and two emissions projections, the loss in SWE ranges between $20.3 \%$ and $27 \%$ per $1{ }^{\circ} \mathrm{C}$ of warming, with an average of $24.6 \%$ per $1{ }^{\circ} \mathrm{C}$. The multi-model average results show consistent precipitation increases with temperature, ranging from 2.1 to 3.3 per $1^{\circ} \mathrm{C}$, with an average of $2.8 \%$ per $1^{\circ} \mathrm{C}$. Our results show a much larger sensitivity of SWE to temperature than in Casola et al. (2009). In part, this is due to the much smaller increases in precipitation with temperature simulated by the climate models than the $5 \%$ they assumed, but this only accounts for a few percentage points. An important difference between the two studies is that Casola et al. (2009) consider only the Puget Sound basin, consisting mainly of the western slopes of the Cascade Range while Elsner et al. (2010) and this study consider the entire state of Washington. It is not immediately clear how the larger domain would affect the sensitivity, however it is likely that the eastern portion of the domain, with significant mid-elevation snowpack, would have greater sensitivity than the Puget Sound basin.

To estimate the change in SWE from these relationships using the WRF temperature and precipitation results, we use the temperature change to obtain an initial SWE change and a predicted precipitation change. Since the WRF projections for precipitation do not match the simple assumptions in Casola et al. (2009) nor the multi-model mean in Elsner et al. (2010), we apply a correction based on the over or under estimate of precipitation relative to the WRF simulation. The correction is 
Table 2 Comparison between the regional simulations, in Elsner et al. (2010), and Casola et al. (2009)

\begin{tabular}{llllll}
\hline Model & $\begin{array}{l}T \\
\text { change }\left({ }^{\circ} \mathrm{C}\right)\end{array}$ & $\begin{array}{l}P \\
\text { change }(\%)\end{array}$ & $\begin{array}{l}\text { SWE } \\
\text { change }(\%)\end{array}$ & $\begin{array}{l}\text { VIC SWE } \\
\text { change }(\%)\end{array}$ & $\begin{array}{l}\text { Casola et al SWE } \\
\text { change }(\%)\end{array}$ \\
\hline ECHAM5-WRF & 1.6 & 5.1 & -32.8 & -40.1 & -29.5 \\
CCSM3-WRF & 1.6 & 1.4 & -73.5 & -42.7 & -32.4 \\
\hline
\end{tabular}

made with the assumption that a marginal percentage point change in precipitation translates directly to a percentage point change in SWE. Results from the WRF simulation, VIC-based sensitivity, and Casola et al. (2009) sensitivity are given in Table 1. For the ECHAM5-WRF simulation, the projected loss in SWE is 7.3 percentage points less than the result inferred from Elsner et al. (2010) and 3.3 points more than from Casola et al. (2009). On the other hand, the CCSM3-WRF result is considerably larger than either estimate, by 30.8 and 41.1 points.

Two effects not considered in this analysis can help explain this disparity. First, the temperature and precipitation changes in the CCSM3-WRF simulation vary considerably by month. Using monthly values provides SWE responses varying from $-19.6 \%$ (for November) to $-74.6 \%$ (for January) using the VIC-based sensitivity. Due to the seasonal cycle of temperature and precipitation, not all months contribute equally to snowpack, and the January value should receive greater weight. A second effect is that temperature and precipitation changes are not uniform across the region, as assumed in the VIC computations. In particular, the increase in temperature and decrease in precipitation for the winter season is greatest over the Cascade crest and Olympics than elsewhere in the state (Figs. 4 and 7). Thus, the impact of the climate projection on snowpack would be much greater than suggested by statewide averages.

The importance of the second effect is seen by considering the changes in SWE with elevation (Table 2). As for the VIC simulations using spatially uniform temperature and precipitation perturbations, the ECHAM5-WRF simulation shows a greater fractional loss of SWE below 1,000 $\mathrm{m}$ than above. The CCSM3-WRF simulation, however, shows a larger loss above 1,000 $\mathrm{m}$. Thus, the high seasonal and spatial heterogeneity in the temperature and precipitation changes represented by the regional model simulations have a considerable effect on the simulated snowpack changes (Table 3).

\subsection{Changes in extreme events}

A key motivation for using regional climate models in climate impacts research is the ability to represent extreme events. By nature, extreme weather occurs rapidly and over a small geographical extent. Extreme seasonal conditions, such as drought, occur more slowly and with larger geographical extent, and typically depend on

Table 3 Changes in Washington-average snowpack at low and high elevations and all elevations

\begin{tabular}{llll}
\hline Model & $<1,000 \mathrm{~m}$ & $\geq 1,000 \mathrm{~m}$ & All elevations \\
\hline ECHAM5-WRF & -65 & -32 & 32 \\
CCSM3-WRF & -59 & -75 & 71 \\
\hline
\end{tabular}


fine-scale interactions between the atmosphere and land surface features such as topography that are not well resolved in global models. Thus, regional climate models are especially well suited to studying these events. Here we present summary statistics for several types of extreme events related to temperature and precipitation. Our analysis follows the approach of Tebaldi et al. (2006) for global climate model analysis and uses parameters defined in Frich et al. (2002).

\subsection{Heat waves and warm nights}

Climate change is predicted to have significant human health consequences due to heat stress in vulnerable individuals. This issue is discussed in detail in Jackson et al. (2010) where the quantitative relationship between heat events and mortality is analyzed, showing that mortality rises significantly after heat waves last for three or more days. Future heat wave frequencies are represented in Jackson et al. (2010) by a uniform perturbation to the historic record since the global climate models do not give good information on the geographic signature of warming or changes in daily variability. Here we use output from the regional models to compute the frequency of heat waves for present and future time periods. We define a heat wave as an episode of three or more days where the daily heat index (Humidex) exceeds $32^{\circ} \mathrm{C}$. Figure 10, top panel, shows the change in the yearly average number of heat waves of 3-day duration simulated by the two regional models from 19701999 to 2030-2059. Both models show a larger increase in heat wave frequency in south-central Washington than elsewhere in the state, with up to 3 more heat waves each year in the future period than in the control period. The CCSM3WRF simulation (Fig. 10, left) also shows considerable increase in heat waves in the lowlands of western Washington, following the more widespread warming in the CCSM3 scenario. Note that this increase in heat waves occurs despite relatively less seasonal-average warming here than the interior. This result suggests that effects that would moderate coastal warming, such as marine cloudiness, are intermittent and have little effect on the frequency and duration of extreme heat events. Although the heat index includes the effect of relative humidity, the large increase in heat wave frequency in south-central Washington is a result of an increase only in temperature since summertime relative humidity remains nearly constant for this region under climate change.

The frequency of warm nights is another measure of persistent heat stress with important impacts. To analyze the change in the frequency of warm nights, we computed the 90 th percentile minimum temperature $\left(T_{\min }\right)$ for each calendar day at each grid point for the twentieth century simulations. The change in the percentage of days where $T_{\min }$ exceeds the twentieth century's 90th percentile is then computed from the twenty-first century simulation as shown in Fig. 10, bottom panel. In comparison to the change in heat-wave frequency, the frequency of warm nights does not show as marked a geographical pattern, but rather closely follows the pattern of summertime warming (Fig. 7).

\subsection{Extreme precipitation}

We use two parameters to analyze changes in extreme precipitation, which yield somewhat different results. An increase in these parameters indicates that more 


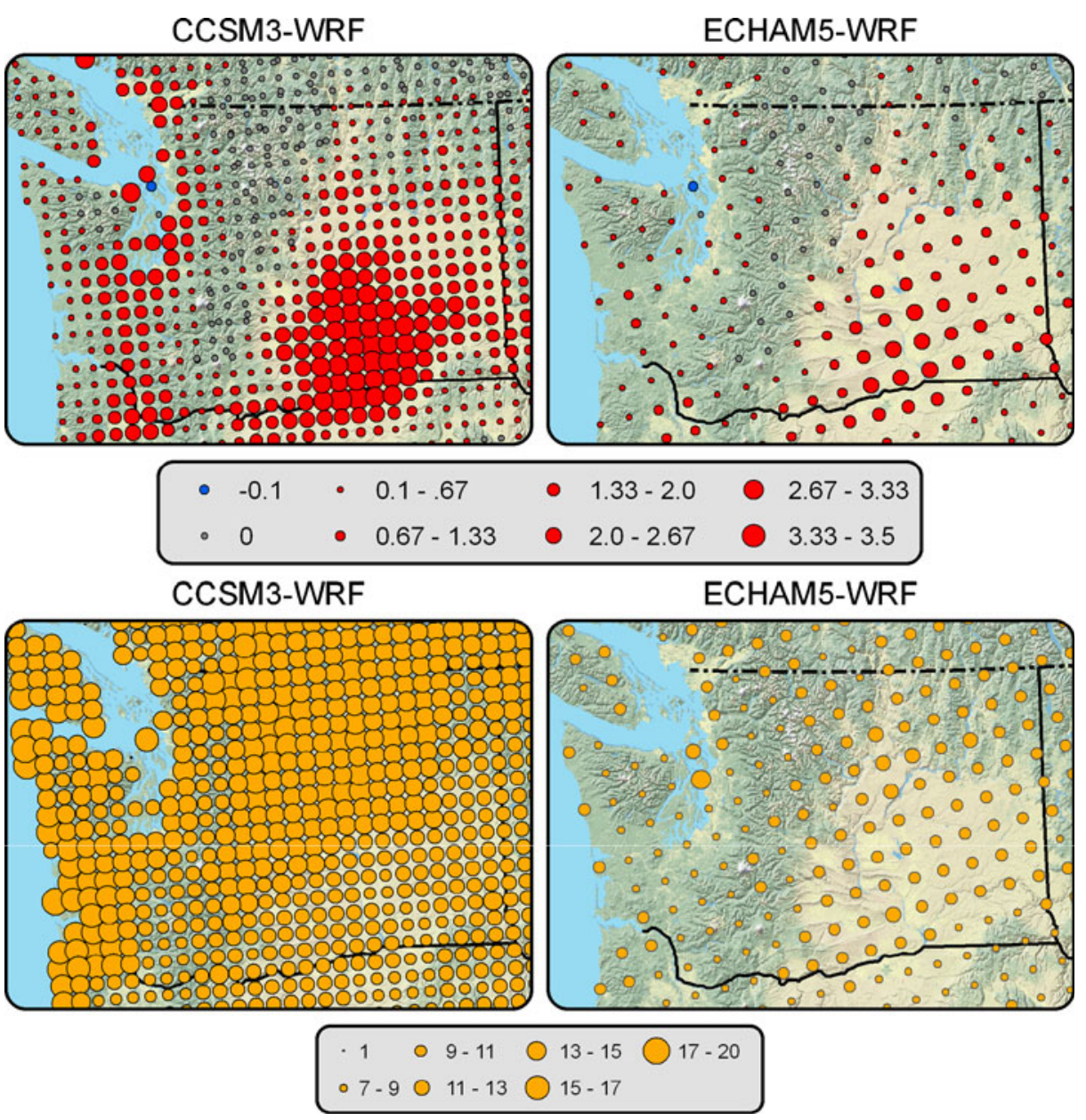

Fig. 10 Top , change in the yearly average number of 3-day heat wave events from CCSM3-WRF (left) and ECHAM5-WRF (right). Bottom, Change in the frequency of warm nights (change in the percent of days with $T_{\min }>90$ th percentile). The size of dots indicates the magnitude of the change; the density of dots indicates the grid spacing the two regional simulations. Figure: Robert Norheim

of the precipitation is coming in extreme events. The first parameter, precipitation intensity, is defined as the annual total precipitation divided by the number of wet days (precipitation exceeding $1 \mathrm{~mm}$ ). Precipitation intensity increases when the annual precipitation increases more rapidly than the number of wet days, indicating more intense precipitation on wet days. The second parameter, R95, is the fraction of precipitation falling on days with precipitation exceeding the 95th percentile for that location, where the 95th percentile is calculated from the twentieth century simulation. An increase in R95 indicates that precipitation in events exceeding the threshold increases more than total precipitation.

For precipitation intensity (Fig. 11), both regional models produce similar results. The change from the current to the future period is positive or very small over the entire state with considerable increases only over the northwestern portion of the 


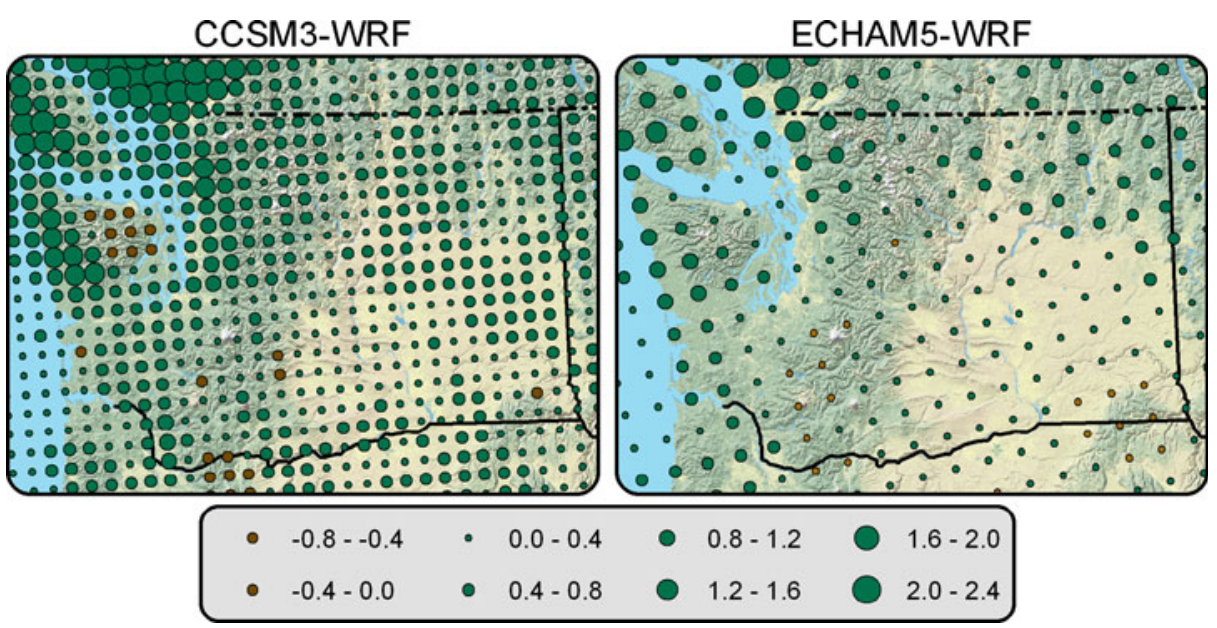

Fig. 11 Change in precipitation intensity in millimeters per day from CCSM3-WRF (left) and ECHAM5-WRF (right). Figure: Robert Norheim

state. The increase appears to follow the southwest, windward flanks of the North Cascades, Olympics, Vancouver Island, and BC Coast Range. The changes in R95 (Fig. 12) are much more widespread, owing in part to the geographical dependence of the threshold. The pattern in the ECHAM5-WRF (Fig. 12, right) simulation is more spatially uniform, with increases in the western and eastern portions of the state and slight decreases in central Washington, along the lee of the Cascades. The CCSM3-WRF (Fig. 12, left) simulation shows much more spatial heterogeneity, likely due to its finer spatial grid and better topographic resolution. In addition, it

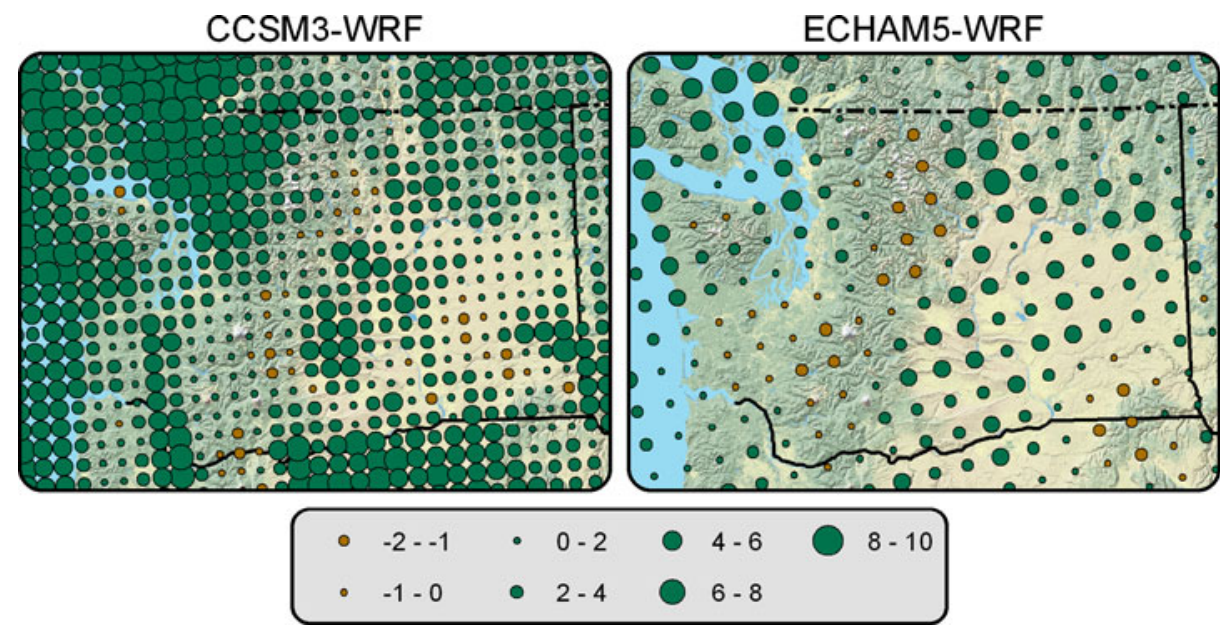

Fig. 12 Change in the percentage of total precipitation occurring when daily precipitation exceeds the 20th century 95th percentile (R95) from CCSM3-WRF (left) and ECHAM5-WRF (right). Figure: Robert Norheim 
is interesting to note that in CCSM3-WRF, both precipitation intensity and R95 increase substantially on the windward slopes of the coastal mountains despite reductions in the total annual precipitation shown in Fig. 4.

As discussed above, the CCSM3 ensemble member used to force the CCSM3WRF simulation has an uncharacteristic increase in November precipitation. To test how critical this result is in determining the change in extreme precipitation, we repeated the above analysis using only data for the months December through February. This restriction makes very little difference for the ECHAM5-WRF simulation, although there is a more pronounced reduction in extremes along the lee of the Cascade Range and a larger increase elsewhere. For the CCSM3-WRF simulation, the increase in extremes for western Washington remains but is reduced; the increase east of the Cascade Range, however, is amplified. Qualitatively, the results based on all months are consistent with the results for the winter months, with some geographical differences.

Consistent with previous findings (e.g., Leung et al. 2004), these results suggest that extreme precipitation changes are more related to increased moisture availability in a warmer climate than to increases in climate-mean precipitation. Although changes in the mean large-scale circulation may not favor precipitation in a climatological sense, increased atmospheric moisture availability under intermittent synoptic conditions favorable for precipitation can lead to increased precipitation intensity and extreme precipitation. This finding has important implications as it suggests that extreme precipitation can increase regardless of the change in total precipitation, which has larger uncertainty as shown in Fig. 4.

\section{Conclusion}

Regional climate models provide important insight into how the regional climate may respond to global climate change. We have presented two long simulations from a mesoscale climate model forced by two global climate model simulations. The object of regional climate modeling is to understand how fine scale weather and landsurface processes respond to the large-scale forcing generated by global models, and how that may alter the local climate change patterns. In overall details, both simulations presented here are quite consistent with the global forcing models used, which is expected. Furthermore, due to the unique characteristics of the forcing models, the fine scale features simulated are substantially different, accentuating differences in the forcing scenarios and underscoring the need for extended simulations using a large ensemble of forcing models and regional models.

The most profound difference between the two simulations is in the cool-season precipitation, which is closely related to the simulated changes in snow pack and temperature. The CCSM3-WRF model shows substantial decreases in winter and spring precipitation. This, combined with a strong warming signal, yields substantial decreases in snow pack along the Cascade Crest and Olympic mountains. Where snow cover is reduced, the warming is locally amplified, suggesting a feedback between precipitation, snowpack, and temperature.

Despite these differences, there are important areas of agreement between the two simulations, suggesting that some local responses to global climate change are robust. Most clear is the loss of snowpack in both simulations. Despite substantial 
differences in the precipitation simulations, both simulations project a similar geographic extent of snow loss and a substantial net loss of snowpack for the state. The reduced snowpack and earlier snowmelt will alter the timing and amount of river runoff in the summer, although changes in annual runoff will depend on annual precipitation changes, which can differ noticeably from one scenario to another.

Changes in extreme events are also similar in the two simulations. Despite modest annual-mean precipitation changes in the CCSM3 and ECHAM5 global climate models, local terrain effects amplify the changes in the regional simulations, with locally opposite signs of changes in some seasons between ECHAM5-WRF and CCSM3-WRF. Yet, both simulations yield an increase in the measures of extreme precipitation even though the CCSM3-WRF simulation produced mostly reductions in total precipitation during winter and spring. Our results show that extreme precipitation increases over the north Cascades and over eastern Washington in both simulations. The geographical distribution of this increase clearly follows the terrain indicating the important role of topography in producing increased precipitation under favorable synoptic conditions with increase moisture availability in a warmer climate.

Our results show that, with increased spatial resolution relative to global models, regional climate models produce local changes in temperature, precipitation, and snowpack in the State of Washington that vary in important ways from the changes inferred from the global models and statistical downscaling. This divergence from the global models is produced by the local forcing of the complex terrain and interactions among changes in temperature, precipitation, and snowpack. Qualitative aspects of these changes are consistent between the two regional simulations, despite differences in seasonal precipitation and temperature changes in the global and regional model results. These results give good guidance to interpreting the results of statistical downscaling, for example, by showing whether orographic precipitation effects are suitably represented in the statistical downscaling. It is clear that changes in the seasonal climate and the frequency of extreme events may be locally much more intense than can be inferred from statistical methods. Consequently, multimodel ensembles of global climate projections and statistical methods may under represent the local severity of climate change. Nevertheless, there is substantial uncertainty in projections of extreme events in regional models, both from simulations with a single model and from multiple models. Quantitative estimates of this uncertainty are required to assess the risk of future extreme events. Future work in regional climate modeling will therefore focus on large ensemble simulations with multiple models to better represent the probability of projected changes.

Acknowledgements This publication is part of the Washington Climate Change Impacts Assessment, funded by the 2007 Washington State Legislature through House Bill 1303. This publication is partially funded by the NOAA Regional Integrated Sciences and Assessments program and the NOAA Climate Dynamics and Experimental Prediction/Applied Research Centers program under NOAA Cooperative Agreement No. NA17RJ1232 to the Joint Institute for the Study of the Atmosphere and Ocean (JISAO). This is JISAO Contribution no. 1787. This work was funded in part by an EPA Science to Achieve Results (STAR) Program (Agreement Number: RD-R833369, EPA has not officially endorsed this publication and the views expressed herein may not reflect the views of the EPA) and by the National Science Foundation (ATM0709856). Computing resources for the WRF simulations were provided by the National Center for Computational Sciences (NCCS) at Oak Ridge National Laboratory through the Climate-Science Computational End Station Development and Grand Challenge Team. PNNL is operated for the US DOE by Battelle Memorial Institute under Contract DE-AC06-76RLO1830. 


\section{References}

Brown RD, Brasnett B, Robinson D (2003) Gridded North American monthly snow depth and snow water equivalent for GCM evaluation. Atmos Ocean 41:1-14

Casola JH, Cuo L, Livneh B, Lettenmaier DP, Stoelinga MT, Mote PW, Wallace JM (2009) Assessing the impacts of global warming on snowpack in the Washington cascades. J Climate 22:2758-2772

Chen F, Dudhia J (2001) Coupling an advanced land surface-hydrology model with the Penn StateNCAR MM5 modeling system. Part I: model implementation and sensitivity. Mon Weather Rev 129:569-585

Collins WD, Rasch PJ, Boville BA, Hack JJ, McCaa JR, Williamson DL, Kiehl JT, Briegleb B, Bitz C, Lin S-J, Zhang M, Dai Y (2004) Description of the NCAR community atmospheric model (CAM 3.0). NCAR Tech. Note, NCAR/TN-464+STR, 226

Collins W et al (2006) The community climate system model version 3 (CCSM3). J Climate 19:21222143

Daly C, Neilson RP, Phillips DL (1994) A statistical topographic model for mapping climatological precipitation over mountainous terrain. J Appl Meteorol 33:140-158

Elsner MM, Cuo L, Voisin N, Deems JS, Hamlet AF, Vano JA, Mickelson KEB, Lee SY, Lettenmaier DP (2010) Implications of 21st century climate change for the hydrology of Washington State. Clim Change. doi:10.1007/s10584-010-9855-0

Frich P, Alexander LV, Della-Marta P, Gleason B, Haylock M, Tank A, Peterson T (2002) Observed coherent changes in climatic extremes during the second half of the twentieth century. Clim Res 19:193-212

Giorgi F, Mearns LO (1999) Introduction to special section: regional climate modeling revisited. J Geophys Res-Atmos 104:6335-6352

Hong SY, Pan HL (1996) Nonlocal boundary layer vertical diffusion in a medium-range forecast model. Mon Weather Rev 124:2322-2339

Hong SY, Dudhia J, Chen SH (2004) A revised approach to ice microphysical processes for the bulk parameterization of clouds and precipitation. Mon Weather Rev 132:103-120

Jackson JE, Yost MG, Karr C, Fitzpatrick C, Lamb BK, Chung S, Chen J, Avise J, Rosenblatt RA, Fenske RA (2010) Public health impacts of climate change in Washington State: projected mortality risks due to heat events and air pollution. Clim Change. doi:10.1007/ s10584-010-9852-3

Kain JS, Fritsch JM (1993) Convective parameterization for mesoscale models: the Kain-Fritsch scheme. In: Emanuel KA, Raymond DJ (eds) The representation of cumulus convection in numerical models. American Meteorological Society, Boston, pp 165-170

Leung LR, Qian Y (2003) The sensitivity of precipitation and snowpack simulations to model resolution via nesting in regions of complex terrain. J Hydrometeorol 4:1025-1043

Leung LR, Qian Y, Bian X (2003a) Hydroclimate of the western United States based on observations and regional climate simulation of 1981-2000. Part I: seasonal statistics. J Climate 16:1892-1911

Leung LR, Qian Y, Bian X, Hunt A (2003b) Hydroclimate of the western United States based on observations and regional climate simulation of 1981-2000. Part II: mesoscale ENSO anomalies. J Climate 16:1912-1928

Leung LR, Qian Y, Bian X, Washington WM, Han J, Roads JO (2004) Mid-century ensemble regional climate change scenarios for the western United States. Clim Change 62:75-113

Leung LR, Kuo YH, Tribbia J (2006) Research needs and directions of regional climate modeling using WRF and CCSM. B Am Meteorol Soc 87:1747-1751

Marsland SJ, Haak H, Jungclaus JH, Latif M, Roske F (2003) The Max-Planck institute global ocean/sea ice model with orthogonal curvilinear coordinates. Ocean Model 5:91-127

Mote PW, Salathé EP Jr (2010) Future climate in the Pacific Northwest. Clim Change. doi:10.1007/ s10584-010-9848-z

Mote PW, Hamlet AF, Salathé EP (2008) Has spring snowpack declined in the Washington cascades? Hydrol Earth Syst Sci 12:193-206

Nakicenovic N et al (2000) IPCC special report on emissions scenarios. Cambridge University Press, Cambridge

Roeckner E, Bengtsson L, Feichter J, Lelieveld J, Rodhe H (1999) Transient climate change simulations with a coupled atmosphere-ocean GCM including the tropospheric sulfur cycle. J Climate 12:3004-3032

Roeckner E, Bäuml G, Bonaventura L, Brokopf R, Esch M, Giorgetta M, Hagemann S, Kirchner I, Kornbleuh L, Manzini E, Rhodin A, Schlese U, Schulzweida U, Tomkins A (2003) 
The atmospheric general circulation model ECHAM5, Part I: model description, Max-Planck Institute for Meteorology Report No. 349

Rosenberg EA, Keys PW, Booth DB, Hartley D, Burkey J, Steinemann AC, Lettenmaier DP (2010) Precipitation extremes and the impacts of climate change on stormwater infrastructure in Washington State. Clim Change. doi:10.1007/s10584-010-9847-0

Salathé EP (2003) Comparison of various precipitation downscaling methods for the simulation of streamflow in a rainshadow river basin. Int J Climatol 23:887-901

Salathé EP (2005) Downscaling simulations of future global climate with application to hydrologic modeling. Int J Climatol 25:419-436

Salathé EP, Steed R, Mass CF, Zahn P (2008) A high-resolution climate model for the U.S. Pacific Northwest: mesoscale feedbacks and local responses to climate change. J Climatol 21:5708-5726

Tebaldi C, Hayhoe K, Arblaster JM, Meehl GA (2006) Going to the extremes. Clim Change 79:185-211

Vano JA, Voisin N, Cuo L, Hamlet AF, Elsner MM, Palmer RN, Polebitski A, Lettenmaier DP (2010) Climate change impacts on water management in the Puget Sound region, Washington, USA. Clim Change. doi:10.1007/s10584-010-9846-1

Widmann M, Bretherton CS, Salathé EP (2003) Statistical precipitation downscaling over the Northwestern United States using numerically simulated precipitation as a predictor. J Climatol 16:799-816

Wood AW, Leung LR, Sridhar V, Lettenmaier DP (2004) Hydrologic implications of dynamical and statistical approaches to downscaling climate model outputs. Clim Change 62:189-216

Zhang Y, Duliere V, Mote PW, Salathé EP (2009) Evaluation of WRF and HadRM mesoscale climate simulations over the U.S. Pacific Northwest. J Climate 22:5511-5526 